\title{
P-SELECTIN GLYCOPROTEIN LIGAND-1 GENE POLYMORPHISMS IN SUDANESE PREGNANT WOMEN WITH THROMBOSIS
}

\author{
ABDELRAHMAN A ELHASSAN ${ }^{1}$, FATHELRAHMAN MAHDI HASSAN ${ }^{2}$, HANAN B ELTAHIR ${ }^{3}$ \\ ${ }^{1}$ Department of Hematology, College of Medical Laboratory Science, Sudan University of Science and Technology, Khartoum, Sudan. \\ ${ }^{2}$ Department of Clinical Laboratory Science, College of Applied Medical Science, Imam Abdulrahman Bin Faisal University, Saudi Arabia. \\ ${ }^{3}$ Department of Biochemistry, Faculty of Medicine and Health Sciences, University of El Imam El Mahadi, Sudan. Email: heltahir@yahoo.co.uk \\ Received: 29 June 2018, Revised and Accepted: 30 July 2018
}

ABSTRACT

Objectives: In this study we aimed to investigate whether P-selectin gene polymorphism is associated with thrombosis in Sudanese pregnant women in Khartoum state.

Methods: After informed consent, 96 Sudanese pregnant women with thrombosis and 53 healthy pregnant women were recruited in the study. Genomic DNA was isolated from whole blood. Genotyping of PSGL-1 gene was performed by polymerase chain reaction amplification for exon 14 and electrophoresis.

Results: The frequency of the B allele was found to be significantly higher in pregnant women with thrombosis (26\%) compared to the controls $(17.4 \%)$.

Conclusion: The AB genotype was found to be higher in women with thrombosis $40.6 \%$ than in healthy controls $20 \%$ ( $\mathrm{p}=0.02$ ). Our results suggest that the PSGL-1 AB genotype is associated with an increased risk of thrombosis in Sudanese pregnant women.

Keywords: P-selectin glycoprotein ligand-1 polymorphisms, Variable number of tandem repeats, Thrombosis, Deep vein thrombosis.

(C) 2018 The Authors. Published by Innovare Academic Sciences Pvt Ltd. This is an open access article under the CC BY license (http://creativecommons. org/licenses/by/4. 0/) DOI: http://dx.doi.org/10.22159/ajpcr.2018.v11i12.28200

\section{INTRODUCTION}

It is well known that normal pregnancy is associated with a hypercoagulable state, resulting in a moderate risk for thrombosis during the different trimesters of pregnancy. From the viewpoint of coagulation/fibrinolysis changes, the follow-up of thrombophilia markers could be recommended when levels of coagulation parameters exceed the normal values during pregnancy [1]. Tissue factor interacts with activated factor VII to initiate a series of coordinated enzymatic reactions leading to the formation of thrombin. Thrombin then converts fibrinogen to fibrin to stabilize the initial platelet plug and to form a fibrin clot [2]. Activation of platelets leads to the exposure of P-selectin on the surface of platelets. P-selectin is an adhesion molecule which mediates the interaction of activated endothelial cells or platelets with leukocytes.

P-selectin concentration had been reported in the blood of patients with thrombotic consumptive platelet disorders, such as disseminated intravascular coagulation [3]. Activated platelets may be sequestered during thrombus formation, and thus, platelet P-selectin may underestimate the actual platelet activation. Activated platelets may also be attached to leukocytes. It was found that platelet-monocyte complexes are better markers for thrombotic tendency than platelet P-selectin that was formerly regarded as the gold standard [4]. Soluble P-selectin may be elevated disproportionately to platelet P-selectin because of the presence of selectin polymorphism that can influence P-selectin shedding [5]. Now the risk of venous thromboembolism (VTE) is increased during normal pregnancy is well known. In Sweden and Norway during the early 1990s, VTE occurred in slightly more than one of 1000 pregnant women [6,7]. There is a continued interest in developing therapeutics to combat human injury sustained from a myocardial infarction. To date, the therapy for acute ischemia of the heart has been largely directed toward reestablishing perfusion of the ischemic myocardium or toward the coagulation system to prevent thrombosis. Therefore, strategies that would improve treatment of different forms of myocardial ischemia are reasonable [8].

P-selectin expressed on activated platelets binds to P-selectin glycoprotein ligand-1 (PSGL-1) on neutrophils, recruits leukocytes into growing thrombi, and promotes fibrin deposition [9]. A significant increase in plasma P-selectin concentration had been reported in blood of patients with thrombotic consumptive platelet disorders, such as thrombotic thrombocytopenia purpura (TTP), or heparininduced thrombocytopenia (HIT). In thrombotic processes, during the association of leukocytes with platelets and endothelial cells [10]. Elevated soluble P-selectin levels are predictors of early adverse events in patients with chest pain presumed caused by myocardial ischemia [11]. Thus, the correct identification of the risk factors associated with the stroke patients prior helps to bring down the cost burden along with improvement in the quality of life effectively [12].

There is a relatively common genetic variation in PSGL-1 with a variable number of tandem repeats (VNTR) affecting the length of the extracellular domain of PSGL-1 molecule through the distance from the P-selectin binding site to the cell surface [13]. Three allelic variants were identified in the human population. The 3 alleles, A, B, and C, from largest to smallest, contained 16,15 , and 14 decameric repeats, respectively, with the $B$ variant lacking repeat 2 and the $C$ variant retaining repeat 2 but lacking repeats 9 and 10 . Allele frequencies were highest for the A variant and lowest for the $\mathrm{C}$ variant; the frequencies were described as $0.81,0.17$, and 0.02 in the Local population. Homozygous carriers for the shorter $\mathrm{B}$ and $\mathrm{C}$ short alleles had a lower risk for premature myocardial infarction due to lower adhesive capacity [14]. Further studies may clarify whether other haplotypes of P-selectin and/or PSGL-1 gene substantially influence the risk and outcomes of adverse vascular events with or without medication [15]. P-selectin is highly polymorphic having several genetic variants; the Thr715Pro variant 
located in the last consensus repeat region of P-selectin is probably the most intensively studied $[16,17]$. The substitution of threonine for proline induces a conformational change in the precursor protein, which may influence its intracellular transportation and secretion leading to reduced expression and/or shedding of P-selectin, and thus, fewer cellular interactions are developed. The Pro715 allele alters the kinetics of P-selectin release in patients with recurrent deep vein thrombosis (DVT) [18].

\section{METHODS}

\section{Subjects}

This study included $96(64 \%)$ pregnant women patients with thrombosis with mean age of $32.56 \pm 3.67$ as the test group and 53 (36\%) healthy pregnant women as the control group with mean age of 32 , standard deviation $=3.66$, attended Khartoum Teaching Hospital, Omdurman Maternity Hospital, and El Shaikh Faddul Maternity Hospital, Khartoum state. They were included during March 2015-June 2017. The diagnosis and classification of thrombosis or DVT were based on information from known DVT- or VTE-hospitalized patients, and it follows inclusion and exclusion criteria that depend on current or previous DVT or VTE or history of thrombosis. Informed consent was obtained from all participants. The demographic data were obtained using pre-designed questionnaire which includes age, number of pregnancies, history of thrombosis in previous pregnancies, and residence. $3 \mathrm{ml}$ venous blood was collected from patients and controls in EDTA as an anticoagulant.

Laboratory analysis (molecular biology techniques)

Genomic DNA - Isolation from blood leukocytes using salting out method $\downarrow$

Electrophoresis of the extracted DNA in agarose gel $\downarrow$

PCR - Amplification of Exons 14 of P-selectin glycoprotein ligand-1 (PSGL-1)

$\downarrow$

Electrophoresis of PCR products

DNA isolation was done using DNA salting out method which is simple, rapid, and of minimum cost. DNA was detected by electrophoresis on agarose gel stained with ethidium bromide, which has an intense fluorescence excited by ultraviolet radiation when complexes with the nucleic acid. Then, the quality and quantity of extracted DNA were then measured using the spectrophotometer at wave length of $260 \mathrm{~nm}$ and $280 \mathrm{~nm}$.

\section{Polymerase chain reaction (PCR)}

Primers were designed using the published data for human PSGL-1 gene exon 14.

Primers sequences:

F primer5'-CCT GTC CAC GGA TTC AGC-3

R primer5'-GGG AAT GCC CTT GTG AGT AA-3

\section{PCR condition}

The readymade intron premix kits for $20 \mu \mathrm{l}$ were used. The PCR condition used is shown in Table 1.

The PCR products were separated on agarose gels and visualized by ethidium bromide staining. Amplicon band size of 558, 528, and $498 \mathrm{bp}$ corresponded to alleles A, B, and C, respectively.
Table 1: PCR conditions for P-selectin glycoprotein ligand-1 and exon 14

\begin{tabular}{lll}
\hline Cycle & Temperate & Time \\
\hline Initial denaturation & $95^{\circ} \mathrm{C}$ & $3 \mathrm{~min}$ \\
Denaturation & $95^{\circ} \mathrm{C}$ & $30 \mathrm{~s}$ \\
Annealing & $60^{\circ} \mathrm{C}$ & $30 \mathrm{~s}$ \\
Extension & $72^{\circ} \mathrm{C}$ & $30 \mathrm{~s}$ \\
Close cycle. Cycle repeated 30 times & & \\
Final extension & $72^{\circ} \mathrm{C}$ & $7 \mathrm{~min}$ \\
\hline
\end{tabular}

PCR: Polymerase chain reaction

\section{Statistical test}

Chi-squaredX test was used to compare the values of the distribution of VNTR genotypes/haplotypes among case patients and control subjects and used to calculate the $95 \%$ confidence intervals and $\mathrm{p}$ values for crude odds ratios (OR). The statistical analysis was performed using IBM SPSS V 22 program.

\section{RESULTS}

The study recruited 149 Sudanese pregnant women Mean age 32 years, Standard deviation $=3.67$, the healthy pregnant women were $53(36 \%)$ and those with thrombosis comprises 96 (64\%). The allelic frequency of the PSGL-1 gene of A, B, and C alleles was found to be $85 \%, 14 \%$, and $1 \%$, respectively (Fig. 1), and in patients (pregnant with thrombosis), there was difference in the frequency of B allele compared with the controls (pregnant without thrombosis) which is statistically significant ( $26 \%$ versus $17.4 \% \mathrm{p}=0.01)$. The $\mathrm{AB}$ genotype was found to be significantly more frequent among pregnant with thrombosis than in controls ( $40.6 \%$ versus $20 \% \mathrm{p}=0.02$ ) (Table 2 and Fig. 2).

\section{DISCUSSION}

P-selectin on the activated platelets and endothelial cells binds to PSGL1 ligand on the monocytes or on the leucocyte-derived microparticles and stimulates tissue factor expression [19]. The P-selectin/PSGL-1 interaction is definitive in inflammation and thrombosis. It has been shown that blockade of P-selectin or PSGL-1 prevents fibrin formation in animal models [20]. Tissue-factor accumulation and fibrin generation were both markedly reduced in mice deficient in P-selectin or PSGL-1 [21]. These findings show that the interaction of P-selectin with PSGL-1 on microparticles is essential for fibrin generation which enhances thrombus formation. In relation to this background, this study was designed to focus on assessing the frequencies of different PSGL-1 polymorphic forms and their relationship with thrombosis in pregnant women. We found that the frequency of $\mathrm{AB}$ genotype was significantly higher in pregnant women with thrombosis compared with pregnant women without thrombosis $(p=0.02)$ which indicates that the presence of PSGL-1 AB genotype might increase the risk of thrombosis in pregnant women, and the same thing with B allele was found at a higher frequency in pregnant women with thrombosis than in healthy controls $(p=0.01)$ which supports the role of the PSGL-1 VNTR polymorphism as a marker of thrombotic disease.

In Sudan, no previous study bound thrombotic pregnant women with PSGL-1 levels or gene polymorphism in patients compared with normal pregnant women that we have done in this study although many studies suggest that there is a strong relationship between PSGL-1 levels and their genetic polymorphisms and thrombosis [18]. A study done by Kappelmayer and Nagy suggests that PSGL- 1 and other selectin ligands represent diagnostic biomarkers and ideal targets for the intervention of thrombosis and cancer [22]. Recently, many studies have demonstrated the functional relevance of PSGL-1 polymorphism and different forms of cardiovascular diseases [23], and this indicates that the P-selectin/ PSGL polymorphism may be important in initiating thrombosis in pregnant women and suggests that detection of P-selectin/PSGL polymorphisms in those categories should be made to avoid pregnancy complications. 
Table 2: Allele frequency and genotype distribution of PSGL-1 VNTR gene polymorphism in thrombotic patients and controls

\begin{tabular}{|c|c|c|c|}
\hline \multirow{2}{*}{$\begin{array}{l}\text { Genotype/ } \\
\text { Haplotype }\end{array}$} & \multicolumn{2}{|l|}{ Thrombosis (DVT) } & \multirow[t]{2}{*}{$\mathbf{p}$} \\
\hline & Patients (pregnant with DVT)/96 & Controls (healthy pregnant women)/53 & \\
\hline Genotype & No. $(\%)$ & No. (\%) & $\mathrm{p}=0.05$ \\
\hline $\mathrm{A} / \mathrm{A}$ & $55(57)$ & $39(75)$ & 0.6 \\
\hline $\mathrm{A} / \mathrm{B}$ & $39(40.6)$ & $10(20)$ & $0 \cdot 021$ \\
\hline $\mathrm{A} / \mathrm{C}$ & - & $2(3.8)$ & $0 \cdot 123$ \\
\hline $\mathrm{B} / \mathrm{B}$ & $2(2.1)$ & $1(1.9)$ & $1 \cdot 0$ \\
\hline $\mathrm{B} / \mathrm{C}$ & - & $1(1 \cdot 0)$ & $0 \cdot 5$ \\
\hline Haplotype/allele & Patients/96 & Controls/53 & $\mathrm{p}=0 \cdot 05^{\dagger}$ \\
\hline A & $71(74)$ & $43(80.7)$ & 1 \\
\hline B & $25(26)$ & $9(17.4)$ & $0 \cdot 01$ \\
\hline $\mathrm{C}$ & - & $1(1.9)$ & 0.62 \\
\hline
\end{tabular}

PSGL-1: P-selectin glycoprotein ligand-1, DVT: Deep vein thrombosis, VNTR: Variable number of tandem repeats

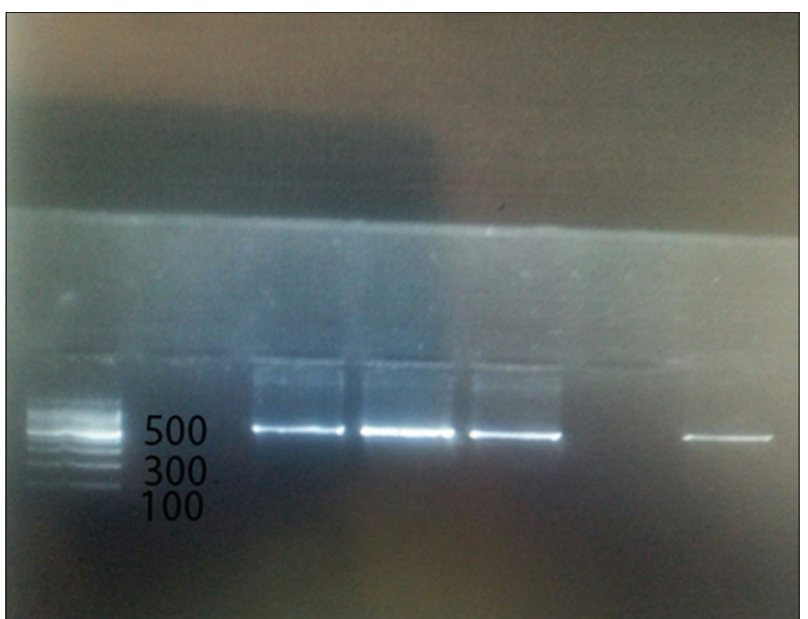

Fig. 1: Polymerase chain reaction products were separated on agarose gels and visualized by ethidium bromide staining. Amplicon band size of 558, 528, and 498 bp corresponded to alleles $A, B$, and $C$, respectively, of $\mathrm{P}$-selectin glycoprotein ligand-1 resolved by $1 \%$ agarose gel with $\times 1$ TBE buffer electrophoresis

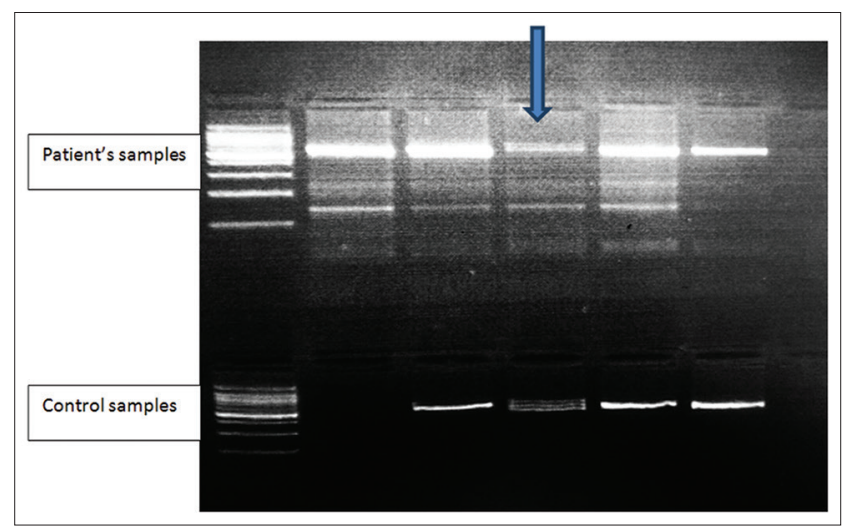

Fig. 2: Control and patients electrophoresis pattern of polymerase chain reaction product of 40-b polymorphism of P-selectin glycoprotein ligand-1 resolved by $1 \%$ agarose gel with $\times 1$ TBE buffer electrophoresis showing AA genotype (blue arrow), while the others (more frequent) were $A B$ genotype

\section{CONCLUSION}

We concluded that the presence of PSGL-1 AB genotype might increase the risk of thrombosis in pregnant women and that the minor B allele results in an increased ability for thrombus formation.

\section{ACKNOWLEDGMENT}

All thanks and appreciation for kind cooperation for College of medical laboratory research lab. (Sudan University of Science and Technology), department of medical laboratory research lab. (Garb Elneil college) and special thanks for Khartoum Teaching Hospital, Omdurman maternity Hospital and El Shaikh Faddul maternity Hospital.

\section{AUTHORS' CONTRIBUTIONS}

Author 1 carried out the experimental part of the work and performed data collection, analysis, and drafted. Author 2 was involved in molecular experimental part of the work, data interpretation, concept, and design. The data interpretation, concept, revision of the work, and correction of the manuscript were done by the corresponding author which is the third author. All authors read and approved the final manuscript.

\section{CONFLICTS OF INTEREST}

We declare that we have no conflicts of interest.

\section{REFERENCES}

1. Borrelli AL, De Lucia D, Bernacchi M, Napolitano M, Di Domenico A, Felicetti M, et al. Haemocoagulative modifications correlated with pregnancy. Minerva Ginecol 2006;58:315-22.

2. Weisel JW. Fibrinogen and fibrin. Adv Protein Chem 2005;70:247-99.

3. El Fekih L, Oueslati I, Hassene H, Fenniche S, Belhabib D, Megdiche ML. Association thromboses veineuses profondes avec tuberculose pulmonaire. Tunis Med 2009;87:328-9.

4. Michelson AD, Barnard MR, Krueger LA, Valeri CR, Furman MI. Circulating monocyte-platelet aggregates are a more sensitive marker of in vivo platelet activation than platelet surface P-selectin: Studies in baboons, human coronary intervention, and human acute myocardial infarction. Circulation 2001;104:1533-7.

5. Nagy B Jr., Csongrádi E, Bhattoa HP, Balogh I, Blaskó G, Paragh G, et al. Investigation of Thr715pro P-selectin gene polymorphism and soluble P-selectin levels in Type 2 diabetes mellitus. Thromb Haemost 2007;98:186-91.

6. Lindqvist P, Dahlbäck B, Marŝál K. Thrombotic risk during pregnancy: A population study. Obstet Gynecol 1999;94:595-9.

7. Jacobsen AF, Skjeldestad FE, Sandset PM. Incidence and risk patterns of venous thromboembolism in pregnancy and puerperium - a registerbased case-control study. Am J Obstet Gynecol 2008;198:233.e1-7.

8. Nabeel K, Manjula SN, Mruthunjaya K, Mahalakshmi AM. Cardio protective effect of Tamarindus indica. Linn against isoproterenol induced myocardial infarction in rats. Int $\mathrm{J}$ Pharm Pharm Sci 2016;8:254-60.

9. Palabrica T, Lobb R, Furie BC, Aronovitz M, Benjamin C, Hsu YM, et al. Leukocyte accumulation promoting fibrin deposition is mediated in vivo by P-selectin on adherent platelets. Nature 1992;359:848-51.

10. Miszti-Blasius K, Debreceni IB, Felszeghy S, Dezso B, Kappelmayer J. Lack of P-selectin glycoprotein ligand-1 protects mice from thrombosis after collagen/epinephrine challenge. Thromb Res 2011;127:228-34.

11. Hillis GS, Terregino C, Taggart P, Killian A, Zhao N, Dalsey WC. Elevated soluble P-selectin levels are associated with an increased risk 
of early adverse events in patients with presumed myocardial Ischemia. Am Heart J 2002;143:235-41.

12. Spurthi T, Rani RK, Navya Y, Swathi D, Kumar RP. Acute post complications in stroke patients visiting a tertiary teaching hospital. Int J Pharm Pharm Sci 2018;10:94-7.

13. Afshar-Kharghan V, Diz-Küçükkaya R, Ludwig EH, Marian AJ, López JA. Human polymorphism of P-selectin glycoprotein ligand 1 attributable to variable numbers of tandem decameric repeats in the mucinlike region. Blood 2001;97:3306-7.

14. Roldán V, González-Conejero R, Marín F, Pineda J, Vicente V, Corral J. Short alleles of P-selectin glycoprotein ligand-1 protect against premature myocardial infarction. Am Heart J 2004;148:602-5.

15. Barbaux SC, Blankenberg S, Rupprecht HJ, Francomme C, Bickel C, Hafner $\mathrm{G}$, et al. Association between P-selectin gene polymorphisms and soluble P-selectin levels and their relation to coronary artery disease. Arterioscler Thromb Vasc Biol 2001;21:1668-73.

16. Herrmann SM, Ricard S, Nicaud V, Mallet C, Evans A, Ruidavets JB, et al. The P-selectin gene is highly polymorphic: Reduced frequency of the pro715 allele carriers in patients with myocardial infarction. Hum Mol Genet 1998;7:1277-84.

17. Csongrádi É, Nagy B Jr., Fulop T, Varga Z, Karányi Z, Magyar MT, et al. Increased levels of platelet activation markers are positively associated with carotid wall thickness and other atherosclerotic risk factors in obese patients. Thromb Haemost 2011;106:683-92.

18. Undas A, Siudak Z, Tracz W. Thr715Pro P-selectin polymorphism and $\mathrm{P}$-selectin release in blood obtained from the bleeding time wounds in patients with deep-vein thrombosis. Thromb Res 2009;124:248-50.

19. van Doormaal FF, Kleinjan A, Di Nisio M, Büller HR, Nieuwland R. Cell-derived microvesicles and cancer. Neth J Med 2009;67:266-73.

20. Myers D, Wrobleski S, Londy F, Fex B, Hawley A, Schaub R, et al. New and effective treatment of experimentally induced venous thrombosis with anti-inflammatory rPSGL-Ig. Thromb Haemost 2002;87:374-82.

21. Falati S, Liu Q, Gross P, Merrill-Skoloff G, Chou J, Vandendries E, et al. Accumulation of tissue factor into developing thrombi in vivo is dependent upon microparticle P-selectin glycoprotein ligand 1 and platelet P-selectin. J Exp Med 2003;197:1585-98.

22. Kappelmayer J, Nagy B. The interaction of selectins and PSGL-1 as a key component in thrombus formation and cancer progression. Biomed Res Int 2017;2017:18

23. Ozben B, Diz-Kucukkaya R, Bilge AK, Hancer VS, Oncul A. The association of P-selectin glycoprotein ligand-1 VNTR polymorphisms with coronary stent restenosis. J Thromb Thrombolysis 2007;23:181-7. 